
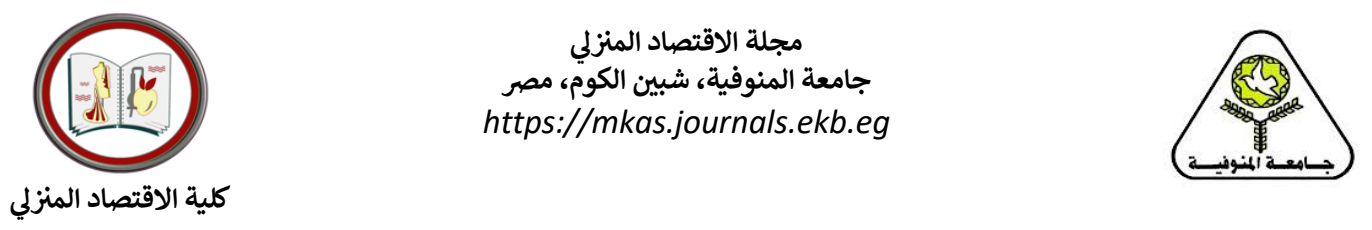

التغذية وعلوم الاطعمة

\title{
ظروف التعبئة وتأثيرها على لون لحم الغنم المجمد وفترة صلاحيته
} نهال محمود الرفاعي

قسم التغذية وعلوم الأطعمة - جامعة ام القرى - المملكة العربية السعودية

\section{ملخص البحث}

تمَّ في هذا البحث استخدام مواد التعبئة (البولي إيثلين المنخفض الكثافة - بولي أميد / بولي إيثلين - بولي فينيل كلوريد)، وتمت التعبئة في ظروف (جو) هوائية - تحت التفريخ، وكانت الدراسة على لحم الغنم في ثلاث صور: مقطع مكعبات بعظم - مقطع مكعبات بدون عظم - مفروم، على أساس أنها الصور الشائعة الاستخدام، تم تعبئته عينات اللَّحم بصورها الثلاث في العبوات المستخدمة وتحت النوعين من ظروف التعبئة المدروسة. كان هدف الدراسة هو دراسة تأثير بعض مواد التعبئة والتغليف على العينات، ودراسة تأثير ظروف التعبئة على العينات المدروسة، ودراسة التغييرات الطبيعية والكيميائية والبكتريولوجية والرائحة في الحالة الطازجة، ثم تمَّ تخزين العينات وحفظها بالتجميد على درجة -18 درجة مئوية لحين رفض العينة حسياً وخلال شهور التجميد حُللت العينات تحليلاً طبيعياً وكيميائياً ومكروبيولوجيا وحسيَّا، لمعرفة مدى تأثير التخزين على فترة صلاحية لحم الغنم المخزن بالتجميد على-18 درجة مئوية لحين رفض العينة حسياً. كانت أهم النتائج والتوصيات هي أفضلية استخدام عبوات البولي أميد/ بولي إيثلين عن البولي فينيل كلوريد، والبولي فينيل كلوريد عن البولي إيثلين، والتعبئة تحت تفريخ أفضل من التعبئة التقليدية، وتخزين اللَّحم بدون عظم أفضل من تخزينه بعظم أو مفروم. الكلمات المفتاحية: لحم الغنم، التخزين، الرائحة، بولي اميد، تحت تفريخ، بولي ايثلين.

JHE, 2021, 31(2): pp 98 - 116 ـ يتم طباعتها في جامعة المنوفية، جميع حقوق الطبع محفوظة للمجلة. 


\section{المقدمة}

التعبئة هي العامل الحاسم في السيطرة على التغييرات غير المرغوبة التي تحدث في القيمة الغذائية للأغذية نتيجة تعرضها للضوء والأوكسجين والرطوبة والتأثير الحراري والتلوث الميكروبي (الشيباني, 1985). ومن المعروف أن وظيفة العبوة هي حماية الأغذية من التلوث والفساد حتى تصل إلى المستهلك في صورة جيدة وأن الكائنات الحية الدقيقة تنمو أسرع داخل العبوات المنفذة للرطوبة والأكسجين المناسب لها وبناء على ذلك يجب تقليل الأوكسجين الملامس للمنتج المعبأ لتقليل الفساد الميكروبي (1991) Hirsch. وبالتالي تساعد التعبئة الجيدة على إطالة فترة صلاحية الأغذية وجودتها لأنها توفر حماية أفضل من المخاطر التي يمكن أن يتعرض لها الغذاء خلال المراحل المختلفة للتصنيع بصفة عامة وخلال التخزين بصفة خاصة (Peter and Axtell , 1993. ويجب أن تكون مواد التعبئة والتغليف المستخدمة للحوم المبردة والمجمدة متينة وسليمة وصحية ولا تسبب أي تغير في خصائص اللحم وألا تنقل إليه أي مواد ضارة بصحة الإنسان أو تلوثه بأي مادة غير مرغوبة وتكون مناسبة ومثبتة بطريقة جيدة على اللحم وأن تكون محكمة القفل غير منفذة للهواء والرطوبة خصوصا عند التعبئة تحت التفريغ (المواصفات القياسية السعودية، 2005).

واستخدمت العديد من الأغلفة البلاستيكية في تغليف المنتجات الغذائية المجمدة ومنها: أغلفة البولي إيثلين Polyethylene (HDPE) High - Density ويوجد نوعان منه البولي إيثلين عالي الكثافة polyethylene غير شفاف يتحمل الحرارة ولكنه اقل استعمالا ، البولي إيثلين منخفض الكثافة (LDPE) أكثر شفافية وسهل القفل حراريا ومقاوم للحرارة ورخيص الثمن لذلك فهو أكثر استعمالا، أغلفة البولي فينيل كلوريد Colyphenyl Chloride (PVC) فقد استعملت لتغليف المنتجات الغذائية لأنها غير منفذة للرطوبة ومعتدلة لنفاذية الأكسجين ، أغلفة البولي أميد / بولي إيثلين Polyamide \Polyethylene وهي عبارة عن مواد بلاستيكية متنوعة متعددة الطبقات تلصق احدها فوق سطح الأخر باستعمال مواد صمغية

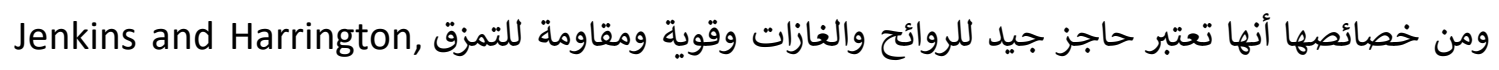

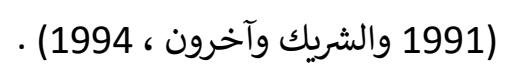

إن فترة صلاحية العديد من الأغذية السريعة الفساد مثل اللحوم والبيض والأسماك والدواجن والخضروات والفاكهة ومنتجات المخابز تكون محدودة في وجود الأوكسجين الجوي بسبب ثلاث عوامل هامة: التأثير الكيميائي

JHE, 2021, 31(2): pp 98 - 116 ـ يتم طباعتها في جامعة المنوفية، جميع حقوق الطبع محفوظة للمجلة. 
للأوكسجين الجوي ونمو الميكروبات الهوائية وهجوم الآفات الحشرية كل هذه العوامل منفردة أو متحدة مع عوامل أخرى تؤدي إلى تغيرات في اللون والنكهة والرائحة وتدهور عام في جودة الأغذية (Smith, et al., 1990). كما توصل (1984) إلى أن الطريقة المفضلة لبيع اللحوم تكون تعبئتها تحت التفريخ under vacuum في أكياس غير منفذة للأوكسجين، حيث إن التعبئة تحت التفريخ أدت إلى المحافظة على جودة اللحوم وإلى تثبيط Sekar المو الميكروبات المسببة للفساد وبالتالي أطالت فترة تخزين اللحم المحفوظ بالتبريد دون تلف. كما أكد et al., (2005) أن تعبئة لحم الجاموس تحت التفريخ أطالت فترة حفظه مع المحافظة على الصفات الطبيعية له مقارنة بالعينات المحفوظة في عبوات محتوية على الهواء. مما سبق يتضح لنا أهمية دراسة تأثير مواد وظروف التعبئة على فترة صلاحية لحم الغنم خلال التخزين بالتجميد.

\section{مشكلة البحث:}

نظرا لأهمية مواد التعبئة والتغليف وظروف التعبئة للمنتجات الغذائية سواء كانت مصنعة أو غير مصنعة ولوجود ندرة في الأبحاث عن دراسة تأثير مواد التعبئة والتغليف وظروف التعبئة على لحم الغنم لذلك من هنا ظهرت

\section{تساؤلات البحث:}

1- هل لمواد التعبئة والتغليف تأثير على فترة صلاحية لحم الغنم المجزأ (قطع مكعبات ومفروم) المخزن بالتجميد

$$
\text { على درجة -18 مِم؟ }
$$

2- هل لجو التعبئة (التعبئة في الهواء - التعبئة تحت التفريخ) تأثير على فترة صلاحية لحم الغنم المخزن لجو

التجميد على درجة -18 مِم؟؟

3- هل لظروف التعبئة (التعبئة في الهواء - التعبئة تحت التفريخ) تأثير على لون أنسجة لحم الغنم المخزن

بالتجميد على درجة -18 우؟

\section{أهمية البحث:}

تصنع مواد التعبئة والتغليف من مكونات عديدة لها خواص كيميائية وفيزيائية متباينة وبعض هذه المكونات يمكن أن يتفاعل مع محتويات الغذاء مؤدية إلى تغير خواصه وبالتالي تؤثر على فترة صلاحية الغذاء، كذلك يكون لظروف تعبئة الغذاء تأثير على خواصه وأيضا على فترة صلاحيته ولذلك فالتعبئة والتغليف وظروف التعبئة الجيدة تعتبر من أساسيات إطالة فترة صلاحية المنتج.

JHE, 2021, 31(2): pp 98 - 116 ـ يتم طباعتها في جامعة المنوفية، جميع حقوق الطبع محفوظة للمجلة. 
18- دراسة تأثير بعض مواد التعبئة والتغليف المختلفة على فترة صلاحية لحم الغنم المخزن بالتجميد على

2- دراسة تأثير ظروف (جو) التعبئة (هوائية - تحت التفريغ) على فترة صلاحية لحم الغنم المخزن بالتجميد على

3- دراسة تأثير ظروف (جو) التعبئة (هوائية - تحت التفريخ) على لون انسجة لحم الغنم المخزن بالتجميد على 우 18-

\section{فروض البحث:}

1- يوجد تأثير لمواد التعبئة والتغليف على فترة صلاحية لحم الغنم المخزن بالتجميد على -18 ㅇ‥ 2- يوجد تأثير لجو التعبئة (هوائية - تحت التفريخ) على فترة صلاحية لحم الغنم المخزن بالتجميد على -18 ِمْ. 3- يوجد تأثير لجو التعبئة (هوائية - تحت التفريخ) على لون انسجة لحم الغنم المخزن بالتجميد على -18 مِم مصطلحات البحث:

Packaging Materials : مواد التعبئة والتغليف

عبارة عن مواد مستخرجة تصنع كنواتج عرضية للبترول وتشكل جميعها حوالي 4\% من البترول الخام (عبد الحميد، 1999) وتعتبر مواد التعبئة والتغليف كمواد مضافة غير مباشرة للأغذية لأنها تلامس الغذاء والمواد الكيميائية الموجودة في تركيبها قد تنتقل إلى الغذاء المعبأ فيها (Jenkins and Harrington , 1991).

\section{2- طروف (جو) التعبئة: packaging condition}

هي الظروف المحيطة بالمنتج المعبأ أثناء تعبئته سواء كانت (وجود الهواء، عدم وجود الهواء، وجود بعض الغازات ) السباعي وآخرون، 2000).

3- 30 - لحم الغنم: Mutton يقصد بلحم الغنم لحم الخروف (الضأن) ovis asies(الشريك وعليان، 1996).

JHE, 2021, 31(2): pp 98 - 116 . يتم طباعتها في جامعة المنوفية، جميع حقوق الطبع محفوظة للمجلة. 


\section{4- التخزين بالتجميد: frozen storage}

هو تخزين المادة الغذائية على درجة حرارة التجميد، الذي يبدأ مباشرة من انتهاء عملية التجميد، ومن خلاله تحتفظ المادة الغذائية بخصائصها المميزة، وتكون ملائمة للاستهلاك، او التصنيع (الشريك وآخرون، 1994).

\section{5- فترة الصلاحية: Shelf - life}

هي الفترة التي يظل فيها الغذاء خلال التخزين في الحدود المقبولة من الجودة . (Hotchkiss, 1988)

\section{6- الميوجلوبين: Myoglobin}

يعتبر الميوجلوبين بروتين رئيسي مسئول عن لون اللحم بالرغم من ان هناك بروتينات أخرى مثل الهيموجلوبين والسيتوكروم تؤثر أيضا على لون اللحم البقري والضأني والدواجن، والميوجلوبين بروتين قابل للذوبان في الماء

.(Mancini and Hunt, 2005)

\section{المفاهيم النظرية للبحث والدراسات السابقة}

اهتم الإنسان باللحوم كمادة غذائية منذ زمن بعيد، ويقصد باللحوم تلك اللحوم الحمراء المشتقة من حيوانات الذبح المختلفة (الماشية، الأبقار، الأغنام، الإبل) واللحوم البيضاء كالدواجن والأسماك، وتمثل اللحوم أهم المصادر الحيوانية لإمداد الخلايا الحية لجسم الإنسان بالبروتين الحيواني الغني بالأحماض الأمينية الأساسية وتتميز اللحوم أيضا بأنها شهية الطعم سريعة الامتصاص في الجسم، وتساهم اللحوم في بناء الخلايا وتعويض التالف منها، وعلى جانب آخر تشكل اللحوم ومنتجاتها مصدرا خطرا على صحة المستهلك إذا تعرضت للتحلل أو التلف أو الفساد أو احتوت على بعض الميكروبات الضارة. (خليفة ومنصور، 1996). يعد الحفظ بالتجميد من أهم الطرق المستعملة لكثير من الأغذية السريعة الفساد حيث انه يحافظ على معظم خواصها الطبيعية وعلى جودتها ويقلل من معظم تفاعلاتها الكيميائية، كما يثبط تكاثر ونمو الكائنات الدقيقة، ويعمل على خفض درجة النشاط المائي للمادة الغذائية وذلك بتحويل معظم محتواها من الماء إلى بلورات ثلجية

عند درجة حرارة -18 مم أو اقل، ويفضل الحفظ بالتجميد لمعظم الأغذية عند هذه الدرجة (الشريك وعليان 
يرتبط تغليف المنتجات المجمدة بنوع المنتج الغذائي والدرجة المطلوبة لحمايته، وفي جميع الأحوال يجب أن يكون التغليف مرتبطا بحفظ المنتجات الغذائية عند درجات حرارة منخفضة، بل يجب أن يكون مرتبطا بمتطلبات التغليف المطلوبة لكل نوع من المنتجات الغذائية وعموماً.

الأغلفة المستخدمة في هذا البحث

\section{Polyethylene (PE) البولي إيثلين}

استخدم Almeida-Dominguez, et al., (1992) البولي إيثلين كمواد تعبئة وتغليف لمنتجات اللحوم لرخص ثمنها وازدادت كفاءة هذه العبوات في المحافظة على جودة اللحم خلال التخزين مع التعبئة تحت التفريخ. ذكر (الشريك وعليان، 1996) أن أغشية أو أغلفة البولي إيثلين تستعمل غالباً في تغليف المنتجات الغذائية لسهولة التعامل معها، كما أنها تتميز بقابليتها للقفل الحراري، ورخص ثمنها فضلاً عن أنها مقاومة للحرارة، وغير منفذة للرطوبة، ولكنها ضعيفة ولا يمكن استعمالها لكثير من المنتجات الغذائية. وفي السنوات الأخيرة كثر استعمال الأغشية الملتصقة أو المطاطة المصنوعة من بولي إيثلين ذات الكثافة المنخفضة في لف المنتجات الغذائية أو التغليف الخارجي لها؛ لما لها من قابلية الالتصاق على المنتج، وعالية المطاطية. وقد زاد استعمالها على حساب الأغلفة المركبة، لرخص ثمنها، بالرغم من بعض عيوبها وكذلك فقد استعملت أغشية البولي إيثلين العالية الكثافة

المبطنة بالرقائق في صناعة أكياس مقاومة لحرارة الغليان. تعتبر أفلام البولي إيثلين أفلام خاملة كيميائيا، وهذا يقودها بالطبع إلى الاستخدام في مجال تغليف الغذاء، ويستخدم كم كبير من الأطنان لصناعة الأكياس التي تستخدمها مباشرة ربة المنزل لتخزين الأطعمة في المبردات، وكذلك في لف وتعبئة الوجبات السريعة وفي منافذ البيع والتجزئة، وكذلك في مجال البقالة، وقد أدت متانة أغلفة البولي اثيلين المنخفضة الكثافة في درجات الحرارة المنخفضة إلى استخدامها في تغليف الغذاء المجمد، وهذا النوع من التغليف أرخص من الكرتون ومفضل عند ربة المنزل لأنه أسهل في الاستخدام، وأيضاً يستخدم في تغليف الفواكه والخضروات. كما تستخدم أغلفة البولي إيثلين المنخفضة الكثافة في تغليف المحاصيل ومنتجات البساتين الطازجة حيث أن متانة الفيلم مطلوبة في تغليف المنتجات الثقيلة مثل البطاطس، وكذلك يستخدم للخضروات الخضراء مثل الخس والكرنب وذلك لخصائص حجز الماء والرطوبة ولتكلفته المنخفضة، هذا وتغليف المنتجات الطازجة يحتاج إلى الاهتمام والعناية حيث أن المنتج بعد عملية الحصاد يستمر في التنفس، ولذا فإن العبوة يجب

JHE, 2021, 31(2): pp 98 - 116 ـ يتم طباعتها في جامعة المنوفية، جميع حقوق الطبع محفوظة للمجلة. 
أن تسمح بدخول الأوكسجين وخروج ثاني أكسيد الكريون، وبالرغم من أن أغلفة البولي إيثلين المنخفضة الكثافة لا تعتبر حاجزاً جيداً للغازات فإن نفاذيتها ليست كبيرة بدرجة كافية تسمح بانتقال الأوكسجين وثاني أكسيد الكريون، لذا فإنه يتم عمل بعض الثقوب الصغيرة في الفيلم، هذه الثقوب تكون كافية لتمنع تراكم غاز ثاني أكسيد الكريون على الفيلم بالإضافة إلى منع تكثف الرطوبة على الفيلم من الداخل مما يؤدي إلى وضوح المحتويات

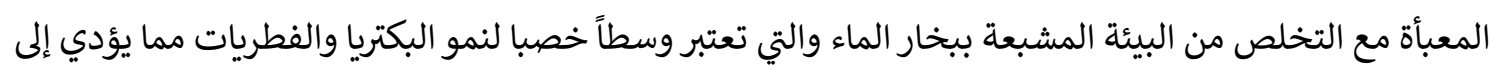
تعفن وفساد المواد المعبأة.

أما البولي إيثلين العالي الكثافة فالفيلم البالغ الرقة منه يستخدم في لف اللحوم، الأسماك، فطائر اللحم، وكذلك يستخدم في مجال البقالة لتحل محل أكياس الورق التقليدية، هذا ويتميز فيلم البولي اثيلين العالي الكثافة بخصائص حجز جيدة خاصة للرطوبة والشحوم ويتميز أيضاً بالمتانة وخفة الوزن ونقطة تليين الفيلم أعلى من درجة غليان الماء مما يسمح بتعقيمه بالبخار، وهذا لا يتوفر لفيلم البولي اثيلين المنخفض الكثافة. (السباعي ومهنا, 2000) استخدم Carpenter et al., (2001) عبوات البولي إيثلين في تعبئة استيك (شرائح) اللحم البقري وأقراص من اللحم البقري المفروم تحت التفريخ حيث وجد أن التعبئة تحت تفريخ حافظت على صفات اللحم المحفوظ في هذه العبوات وكانت التغييرات في استيك اللحم اقل من التغييرات التي حدثت في أقراص اللحم المفروم

\section{Poly Vinyl Chloride (PVC) البولي فينيل كلوريد}

وجد (1980) أن هناك أغشية بلاستيكية عديدة تستخدم في تعبئة وتغليف اللحم الطازج وقد وجد أن أكثر هذه الأغشية استخداماً البولي فينيل كلوريد (PVC) التي استخدمها في تعبئة اللحم البقري. وجد (1982) أنه زاد إنتاج البولي فينيل كلوريد كمواد تعبئة وتغليف على مستوى العالم وتوجد منه عبوات عديدة منها العبوات البلاستيكية والرقائق والأغلفة وتستخدم هذه العبوات بكثرة في تعبئة الأغذية. قرر (Bailey أنه يجب أن تكون لمواد التعبئة والتغليف خصائص عديدة لكي تصلح لتعبئة وتغليف اللحوم ومن دراسته وجد أن أكثر الأغلفة المستخدمة لهذا الغرض البولي فينيل كلوريد والبولي إيثلين حيث تتصف أنها منفذة جيدة للأكسجين ومانعة لمرور بخار الماء وهي مطاطة وتنكمش على المنتج لتعطيه الحماية المناسبة خلال فترة التخزين والعرض للبيع.

JHE, 2021, 31(2): pp 98 - 116 ـ يتم طباعتها في جامعة المنوفية، جميع حقوق الطبع محفوظة للمجلة. 
استخدم Lynch et al., عبوات البولي فينيل كلوريد (PVC) لتعبئة اللحم البقري المفروم تحت التفريخ. وأكد (PVC) أن أغلفة البولي فينيل كلوريد (PVC) كانت حاجز جيد للرطوبة وحاجز فقير للأوكسجين ولهذه الأسباب استخدمها في تغليف اللانشون واللحم والجبنة ومنتجات أخرى.

استخدم Carpenter, et al., (2001) عبوات البولي فنيل كلوريد في تعبئة استيك اللحم البقري وأقراص اللحم البقري تحت التفريغ. استخدم (2004) أغلفة البولي فنيل كلوريد المطاطية البلاستيكية في تغليف اللحم الطازج المباع بالتجزئة.

\section{ثالثاً: البولي أميد/بولي إيثلين Poly Amide Polyethethylene (PA/PE)}

يستخدم لفظ البولي أميد لراتنجات البوليمرات المصنعة ببلمرة التكثيف لحمض عضوي وأمين، وكان (نايلون)

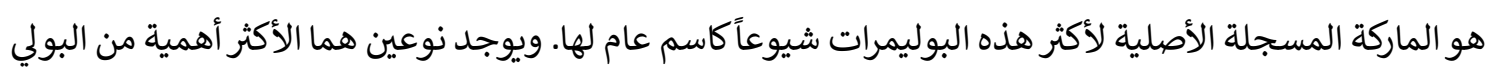
أميدات وهما: 6نايلون، 6.6 نايلون. يعتبر (نايلون 6) هو أكثر النوعين انتشاراً في التعبئة والنايلون عبارة عن أغشية شفافة ذو حجب جيد للروائح والغازات ولكن حجبه للرطوبة ضعيف ويتسم بقوة عالية وتحمل كبير للتمزق والثقوب ويحافظ على خصائصه الميكانيكية بشكل جيد في درجات الحرارة العالية، وبمقارنته بـ البولي إيثلين والبولي فينيل كلوريد نجده أقل استخداما بالرغم من خصائصه الجيدة.(Jenkins and Harrington, 1991 ) وقد تم تطوير أغلفة البولي أميدات بحيث تجمع بين القوة والشفافية الممتازة والمعدلات المنخفضة جداً لنقل الأكسجين (Jenkins and Harrington, 1991). ذكر (Risch and Hotchkiss (1991) أن النايلون يستخدم بدرجة كبيرة في تعبئة وتغليف اللحوم ومنتجات الألبان المعبأة تحت التفريـغ.

ظروف التعبئة وتأثيرها على فترة صلاحية اللحوم: 1- فترة الصلاحية: 1 فترة الصلاحية هي الفترة التي يظل فيها المنتج الغذائي أو الغذاء بصفة عامة خلال التخزين محتفظاً بصفاته الحسية والغذائية ويكون ملائم للاستهلاك الآدمي والتصنيع.

JHE, 2021, 31(2): pp 98 - 116 ـ يتم طباعتها في جامعة المنوفية، جميع حقوق الطبع محفوظة للمجلة. 
وتعتمد فترة الصلاحية للمنتجات على جودة المواد الخام وخطوات التصنيع الجيدة التي تتضمن النظافة ودرجات الحرارة الثابتة إلى حد معقول والظروف المحيطة، وتعتمد فترة الصلاحية أيضاً اعتماداً كبيراً على الظروف التي يتم

تعبئة الغذاء بها وعلى ظروف التخزين ( www.fao.org). التعبئة وسيلة لتصحيح الظروف البيئية للغذاء خلال إطالة الوقت من تخزينه أو توزيعه للمستهلك ولذلك التعبئة الجيدة تحافظ على نظافة المنتج من الأترية والتلوث وتمنع الفقد من العناصر الغذائية والفقد من الرطوبة وتعمل على حماية الأغذية أثناء التداول والنقل والتوزيع والتخزين والتسويق، أيضاً تحمي الغذاء من التغيرات الكيميائية والطبيعية والإصابة بالحشرات والقوارض والتلوث الميكروبي ( www.fao.org). يجب أن يؤخذ في الاعتبار أن تعبئة اللحوم تعمل على إطالة وقت التخزين بالتجميد عن حفظ اللحوم بدون

عبوات. (Cutting 1974) معرفة فترة صلاحية المنتج في ظل الظروف التجارية والواقعية تعطي للسلطات المختصة الإمكانية في تحديد فترات انتهاء الصلاحية التي يتمتع المستهلك خلالها بالثقة في المنتجات التي يستهلكها، ويكون هذا النظام لتاريخ الصلاحية جزء من الاستراتيجية القومية التي تتبناها المملكة العربية السعودية لضمان حماية المستهلك ولذلك يفضل أن تكون فترات انتهاء الصلاحية قصيرة بحيث تضمن منتج ذو قابلية فيما يتعلق بالشروط الصحية والحسية وشروط التعبئة والنقل. (1986) SASO وبالتالي تكون التعبئة أحد الوسائل المستخدمة لضمان جودة المنتج على

الأقل بإطالة فترة صلاحيته. (Hotchkiss, 1988). تحتاج بعض المنتجات الغذائية إلى أجواء خالية من الأوكسجين، وعندما يتطلب الأمر تخزين المنتجات لمدة طويلة يفرغ الهواء من العبوه تفريغا جزئيا أو يخلل الهواء ثم تخزن بعد ذلك وتطبق هذه التقنية للعبوات المقاومة للحرارة والأكياس القابلة للتشكيل (الشريك وآخرون، 1994)

\section{2- تأثير التعبئة تحت التفريخ على فترة الصلاحية:}

عند عرض قطع اللحم الكبيرة للبيع بالجملة في الأسواق تكون الطريقة المفضلة لحفظها تعبئتها تحت التفريخ في عبوات مغلقة غير منفذة للأوكسجين لأنه وجد أن التعبئة تحت التفريخ من الطرق الممتازة لتعبئة اللحم الطازج وللحفاظ على جودته حيث إن الجو المحيط باللحم داخل هذه العبوات يثبط النمو الميكروبي للميكروبات

Bailey,1984).(الموجودة طبيعيا مع اللحم

JHE, 2021, 31(2): pp 98 - 116 ـ يتم طباعتها في جامعة المنوفية، جميع حقوق الطبع محفوظة للمجلة. 


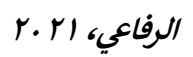

يعد زمن وطريقة التخزين من العوامل الهامة المؤثرة على الحفاظ على جودة اللحم الطازج وتعتبر التعبئة تحت التفريخ طريقة حفظ ذات مميزات أفضل بما أنها تستعمل أقل مساحة وتسمح بتحسين الليونة الناتجة عن التعتيق بدون الفقد بالتبخر (المحافظة على محتوى الرطوية) وذات فترة تخزين (فترة الصلاحية) أطول ومن الناحية الميكروبية (يكون عدد الميكروبات قليل جداً خلال فترة التخزين) بالمقارنة بالطرق الهوائية (Bohme, 1986). درس Goktan, et al., (1988 تأثير التعبئة تحت التفريخ والتعبئة في الظروف الهوائية على فترة صلاحية عينات

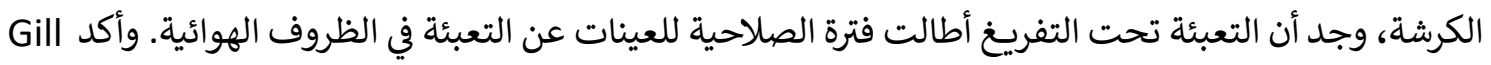
and Harrison (1989) أن فترة التخزين بالتبريد للحم المعبأ تحت التفريخ طالت أريع أضعاف من اللحم المعبأ

وجد (1997) Sheridan et al., عند تعبئة أكتاف لحم الغنم تحت التفريخ وتخزينها على درجتي حرارة 5، صفر oِم أن التعبئة تحت التفريخ أطالت فترة صلاحية اللحم نتيجة لتقليل أو تثبيط النمو الميكروبي لهذه العبوات. وجد (2002) Mermelstein أن فترة صلاحية المنتج الغذائي تعتمد على طبيعة المنتج وتكنيك الحفظ المستخدم والظروف البيئية التي يتعرض لها المنتج وبالتالي هناك 4عوامل رئيسية تؤثر على إطالة فترة صلاحية المنتج وهي: تركيب المنتج - التصنيع - التعبئة - ظروف التخزين، وجد أن اللحم وجودته أيضاً يؤثر على فترة صلاحية اللحوم خلال تخزينه حيث إن اللحم الخام ذو الجودة العالية إذا حُفظ في ظروف جيدة وعبوات مناسبة يطيل ذلك من فترة صلاحيته وبالتالي مواد التعبئة وظروف التعبئة الجيدة تعمل على المحافظة على جودة اللحوم ومنتجاتها وقد وجد أن ظروف التعبئة المعدلة أي إن كانت التعبئة تحت التفريخ أو في جو معدل من الغازات تعمل على إطالة فترة صلاحية اللحوم ومنتجاتها. استنتج (2003) أن تعبئة الأغذية الجاهزة للأكل تحت التفريخ على درجة و303م أطالت فترة صلاحيتها إلى 29 يوم في الوقت الذي كانت فيه فترة صلاحية العينات المعبأة بدون استخدام التفريخ 7 أيام فقط. التغييرات في لون أنسجة لحم الغنم خلال التخزين بالتجميد

Jeremiah et al., قد يكون اللون من أهم الخصائص المؤثرة على قرار المستهلك بقبول اللحوم ومنتجاتها. (1972) حيث أن هناك زيادة خطية في رفض المستهلك للحم الباهت اللون وكذلك عندما تزداد نسبة صبغة Hood and الميتاميوجلوبين البنية اللون التي وجدت في دراسة تغيرات اللون باللحم البقري الطازج بواسطة

JHE, 2021, 31(2): pp 98 - 116 . يتم طباعتها في جامعة المنوفية، جميع حقوق الطبع محفوظة للمجلة. 


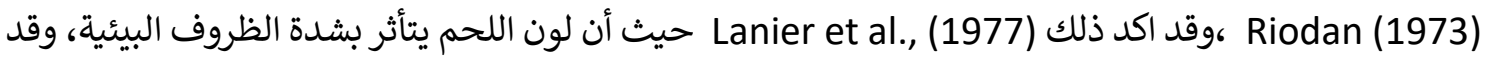
ينتج اللون البني للحم (من تكون الميتاميوجلوبين) نتيجة أكسدة الأحماض الدهنية غير المشبعة وتكوين البيروكسيدات التي تؤثر على لون اللحم ،وذكر(Rhee and Ziprin أن الميتاميوجلوبين يتكون نتيجة لأكسدة داي اوكسي ميوجلوبين Deoxymyoglobin والاكسي ميوجلوبين Oxymyoglobin وهذا يسبب تغييرات واضحة في لون اللحم (Hunt (1980) ووفي اللحم الطازج تتأثر الكمية الكلية من الميتاميوجلوبين أساسا بانخفاض قدرة العضلة، الأكسجين المتاح، درجة الحرارة وفي اللحم المجمد تغييرات اللون تتأثر بوقت ودرجة

حرارة التخزين ودورات التجميد والانصهار والتعرض للضوء. (MacDougall, 1982) يستخدم المستهلك لون اللحم كمقياس لدرجة طزاجتها وجودتها ودائما يتطلب في اللحم اللون الأحمر اللامع للحم الطازج قبل التعبئة. (1980) Hood لون الأنسجة العضلية الخام يقدر بواسطة حالة الأكسدة من صبغة الميوجلوبين الموجودة في العضلات Ledward (1984) واختزال صبغة الميوجلوبين الى ديوكسي ميوجلوبين يكون مسئول عن اللون الأرجواني لقطع اللحم الطازج كما في اللحم المحفوظ تحت ظروف Deoxymyglobin غير هوائية (تحت التفريخ على سبيل المثال) وهذا الشكل من الميوجلوبين غير ثابت نسبيا حيث عندما يتعرض اللحم ثانيا للهواء يزهو اللون مرة أخرى لان داي اكسي ميوجلوبين يتأكسد بسرعة لللاكسي ميوجلوبين ذو اللون الأحمر اللامع (Baiely,1984) يعتبر لون اللحم الطازج خاصية هامة في الجودة وعامل هام يؤثر في قرارات الشراء بالتجزئة ويمكن للتعبئة تحت التفريخ أن تحافظ على لون اللحم حيث تعتبر طريقة شائعة تستخدم لتوزيع اللحم ولكنها تعطي للحم اللون الأرجواني الناتج لتكون ديوكسي ميوجلوبين Deoxymyglobin إلا أنها تحافظ على اللون خلال فترة التخزين، والعينات غير الهوائية تقلل النمو الميكروبي وتحسن فترة الصلاحية لكن المستهلك عموما يفضل لون اللحم

(Meischen, et al.,1987). البقري اللامع عن منتجات اللحم البقري المعبأة تحت التفريخ الغامقة اللونية أساليب وحدود وإجراءات البحث

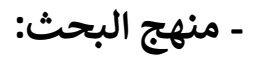
يتبع هذا البحث بإذن الله المنهج التجريي المبني على أسلوب المجموعات المتكافئة، حيث تستخدم أكثر من مجموعة، ويدخل العامل التجريي على إحداها، وتترك المجاميع الأخرى في ظروفها الطبيعية (عبيدات، 2003). 


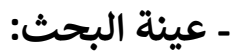

أ- لحم غنم طازج (مقطع مكعبات بدون عظم - مقطع مكعبات بعظم - مفروم) . ب- مواد التعبئة والتغليف (بولي إيثلين منخفض الكثافة، بولي أميد، بولي فينيل كلوريد).

\section{- خطوات البحث: - (}

أولا: تحضر عينات لحم الغنم التي كانت عبارة عن 27 فخد وتم تقسيمها إلى ثلاث أقسام لحم بدون عظم وبعظم ومفروم ويعبأ 200جم من كل قسم في الثلاث أنواع من مواد التعبئة والتغليف المستخدمة في هذا البحث في الظروف الهوائية(تعبئة تقليدية) ليصبح لدينا 9 عينات ثم يعبا الجزء الآخر من العينات في ظروف تحت التفريخ باستخدام مكينة موديل 840X560X180mm وطولها J-V006 - بعدا لعبوات البولي أميد وعبوات البولي إيثلين واستخدام مكينة موديل SL 56 لعبوات البولي فينيل كلوريد فيصبح لدينا 9 عينات وبالتالي

$$
\text { يكون عدد جميع العينات } 18 \text { عينة. }
$$

ثانيا: تحلل عينة واحدة من اللحم الطازج (zero time) تدل على الثلاث أنواع من التقسيمات السابقة لحم بدون

$$
\text { عظم وبعظم ومفروم. }
$$

ثالثا: تخزن الـ 18 عينة المعدة في الخطوة الأولى بالتجميد على درجة -18 مم وتحلل شهريا إلى أن ترفض آخر عينة حسيا عن طريق التقييم الحسي للرائحة فقط (هل هي طبيعية ومقبولة أم غير طبيعية وغير مقبولة).

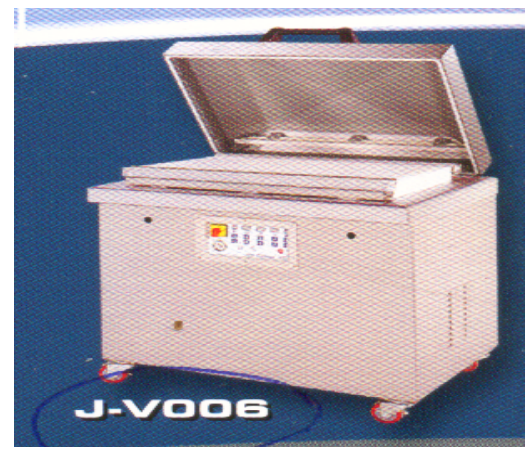

الشكل (1): ماكينة التعبئة تحت التفريغ لعبوات البولي اميد / بولي إيثلين وعبوات البولي إيثلين

JHE, 2021, 31(2): pp 98 - 116 . يتم طباعتها في جامعة المنوفية، جميع حقوق الطبع محفوظة للمجلة. 


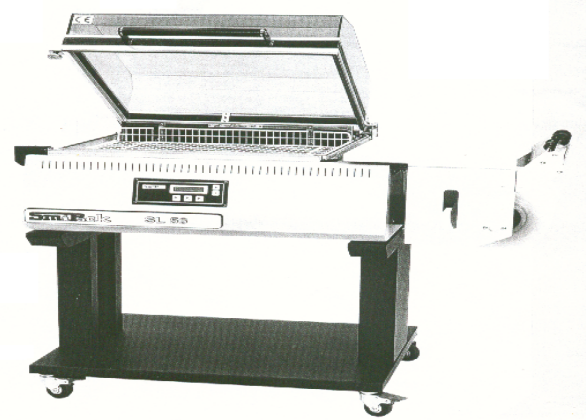

الشكل (2): ماكينة التعبئة تحت التفريخ لعبوات البولي فينيل كلوريد.

\section{ملخص النتائج}

تم في هذا البحث دراسة تأثير ظروف التعبئة على فترة صلاحية لحم الغنم خلال التخزين بالتجميد على -18مْ، حيث تم تعبئة لحم الغنم في ثلاث صور (بدون عظم وبعظم ومفروم) في ثلاثة أنواع من مواد التعبئة والتغليف (البولي إيثلين PE والبولي فينيل كلوريد PVC) تحت ظروف البولي أميد / بولي إيثلين PA/PE) تحت تفريغ)

\section{وفيما يلي ملخص النتائج التي تم الحصول عليها:}

هناك اختلافات واضحة بين العينات المعبأة في الهواء والمعبأة تحت التفريغ، تدل على ان التعبئة تحت التفريخ أفضل في حفظ جودة اللحم خلال التخزين بالتجميد وتعمل على إطالة مدة التخزين (فترة الصلاحية). هناك اختلافات واضحة بين كل عامل ووقت التخزين حيث تدل على تأثير التخزين بالتجميد على صفات الجودة للحم، ولكن كانت فترة الصلاحية للحم مع التعبئة تحت تفريغ أطول مع العينات المعبأة في الهواء هناك اختلافات واضحة بين العينات تدل على ان نوع اللحم أو القطعة من اللحم تؤثر على فترة صلاحيته حيث إن فترة الصلاحية كانت أطول مع اللحم بدون عظم، يليها اللحم بعظم، ثم المفروم. لنوع العبوة تأثير على فترة صلاحية اللحم المخزن بالتجميد حيث كانت العينات المعبأة في عبوات البولي إيثلين اقل فترة صلاحية والعينات المعبأة في عبوات البولي أميد بولي إيثلين أطول في فترة الصلاحية. وجد ان عينات اللحم المعبأة تحت تفريخ تأخذ اللون الارجواني، ولكن بمجرد فتح العبوة لتقدير اللون، يرجع اللون الى الأحمر الزاهي المميز للحوم وبالتالي تحافظ التعبئة تحت تفريخ على لون اللحم وجودته.

JHE, 2021, 31(2): pp 98 - 116 . يتم طباعتها في جامعة المنوفية، جميع حقوق الطبع محفوظة للمجلة. 


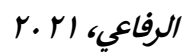

العينات المعبأة في البولي أميد بولي إيثلين كانت أقل انخفاضا في درجات اللون عن المعبأة في البولي فينيل كلوريد والانخفاض الأكبر في درجات اللون كان لعينات اللحم المعبأة في البولي إيثلين. عينات اللحم بدون عظم احتفظت بلونها عن اللحم بعظم واللحم المفروم حيث وجد أن تغييرات اللون أقل في اللحم الكامل عن المفروم.

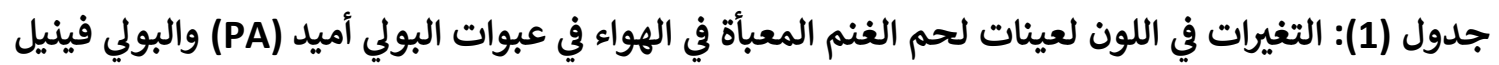

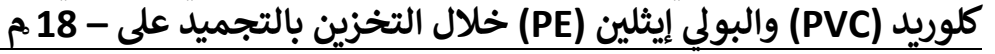

\begin{tabular}{|c|c|c|c|c|c|c|c|c|c|}
\hline \multicolumn{3}{|c|}{ لحم مفروم } & \multicolumn{3}{|c|}{ لحم بعظم } & \multicolumn{3}{|c|}{ لحم بدون عظم } & \multirow{2}{*}{ فالشترة التخزين } \\
\hline PA & PVC & $\mathrm{PE}$ & PA & PVC & PE & PA & PVC & $\mathrm{PE}$ & \\
\hline 1.49 & 1.49 & 1.49 & 1.49 & 1.49 & 1.49 & 1.49 & 1.49 & 1.49 & 0 \\
\hline 1.43 & 1.40 & 1.38 & 1.45 & 1.42 & 1.39 & 1.46 & 1.44 & 1.41 & 1 \\
\hline 1.34 & 1.31 & 1.26 & 1.37 & 1.33 & 1.28 & 1.39 & 1.36 & 1.32 & 2 \\
\hline 1.25 & 1.20 & 1.14 & 1.30 & 1.24 & 1.19 & 1.32 & 1.29 & 1.23 & 3 \\
\hline 1.16 & 1.10 & 1.01 & 1.22 & 1.15 & 1.08 & 1.25 & 1.21 & 1.14 & 4 \\
\hline 1.08 & 1.00 & 0.89 & 1.14 & 1.07 & 0.99 & 1.18 & 1.13 & 1.06 & 5 \\
\hline 0.99 & 0.90 & 0.80 & 1.06 & 0.98 & 0.89 & 1.11 & 1.05 & 0.97 & 6 \\
\hline 0.90 & 0.80 & 0.71 & 0.98 & 0.89 & 0.79 & 1.04 & 0.97 & 0.88 & 7 \\
\hline 0.81 & 0.71 & 0.62 & 0.90 & 0.80 & 0.70 & 0.97 & 0.89 & 0.79 & 8 \\
\hline 0.72 & 0.62 & 0.53 & 0.82 & 0.71 & 0.61 & 0.90 & 0.81 & 0.70 & 9 \\
\hline 0.64 & 0.53 & 0.44 & 0.74 & 0.63 & 0.52 & 0.83 & 0.73 & 0.62 & 10 \\
\hline 0.55 & 0.42 & 0.35 & 0.66 & 0.54 & 0.41 & 0.76 & 0.65 & 0.53 & 11 \\
\hline
\end{tabular}

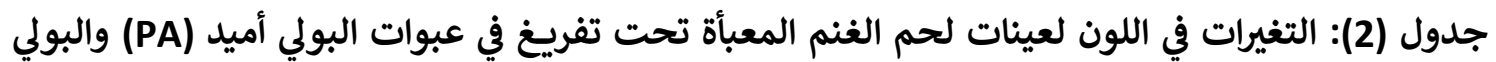

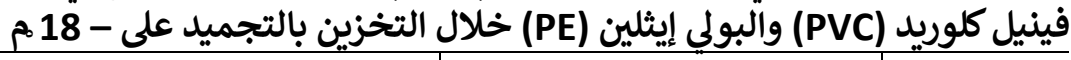

\begin{tabular}{|c|c|c|c|c|c|c|c|c|c|}
\hline \multicolumn{3}{|c|}{ لحم مفروم } & \multicolumn{3}{|c|}{ لحم بعظم } & \multicolumn{3}{|c|}{ لحم بدون عظم } & فترة التخزين \\
\hline PA & PVC & PE & PA & PVC & $P E$ & PA & PVC & PE & بالشهور \\
\hline 1.49 & 1.49 & 1.49 & 1.49 & 1.49 & 1.49 & 1.49 & 1.49 & 1.49 & 0 \\
\hline 1.45 & 1.42 & 1.40 & 1.47 & 1.44 & 1.41 & 1.48 & 1.46 & 1.43 & 1 \\
\hline 1.38 & 1.35 & 1.32 & 1.40 & 1.37 & 1.34 & 1.42 & 1.39 & 1.36 & 2 \\
\hline 1.31 & 1.27 & 1.23 & 1.34 & 1.30 & 1.26 & 1.36 & 1.33 & 1.29 & 3 \\
\hline 1.24 & 1.19 & 1.14 & 1.27 & 1.23 & 1.18 & 1.30 & 1.26 & 1.22 & 4 \\
\hline
\end{tabular}

JHE, 2021, 31(2): pp 98 - 116 . يتم طباعتها في جامعة المنوفية، جميع حقوق الطبع محفوظة للمجلة. 


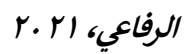

\begin{tabular}{c|c|c|c|c|c|c|c|c|c}
\hline 1.17 & 1.12 & 1.05 & 1.21 & 1.16 & 1.11 & 1.24 & 1.20 & 1.15 & 5 \\
\hline 1.10 & 1.04 & 0.97 & 1.15 & 1.09 & 1.03 & 1.19 & 1.14 & 1.08 & 6 \\
\hline 1.03 & 0.97 & 0.88 & 1.08 & 1.02 & 0.96 & 1.13 & 1.07 & 1.01 & 7 \\
\hline 0.96 & 0.89 & 0.79 & 1.02 & 0.95 & 0.88 & 1.07 & 1.01 & 0.94 & 8 \\
\hline 0.89 & 0.81 & 0.71 & 0.95 & 0.88 & 0.80 & 1.01 & 0.94 & 0.87 & 9 \\
\hline 0.82 & 0.74 & 0.62 & 0.89 & 0.81 & 0.73 & 0.95 & 0.88 & 0.80 & 10 \\
\hline 0.75 & 0.66 & 0.53 & 0.83 & 0.74 & 0.65 & 0.89 & 0.82 & 0.73 & 11 \\
\hline
\end{tabular}

\section{REFRENCES:}

1-Almeida-Dominguez, N.G.; Higuera-Ciapara, I.; Goycoolea, F.M. and Valencia, M.E. (1992): Pack temperature and TBHQ effects on oxidative deterioration of corn-based snacks. J. Food Sci.,57:112- 117.

2- Bailey, AJ.(1984): The Chemistry of Vacuum and GasPackaging of Meat.Ch.11.In:Recent Advances in the Chemistry ofMeat, P.213.The Royal Society of Chemistry, Burlington House, London

3- Bohme, CF. (1986): Maduracion Y conservacion de la carne en sacos de laminas compuestas. Alimentacion Equipos Y Technologia, 5(V):117-124 .C.F.Meat Sci.,73:102108(2006).

4-Carpenter, CE, Cornforth D.P. and Whitter, D.(2001): Consumer Preferences for beef color and packaging did not affect eating satisfaction. Meat Sci.,57:359-363.

5-Cutting C (1974): Weight Losses in Meat, some Significant Factors. Meat Research Institute. Memorandum, No.4, Langford.

6- Gill, C.O. and Harrison, C.L. (1989): The storage life of chilled pork packaged under carbon dioxide. Meat Sci.,26:313-324 .

7- Goktan, D:, Tuncel, G. and Unluturk, A.(1988) : The effect of vacuum packaging and gaseous atmosphere on microbial growth in tripe. Meat Sci.,24(4):301-307 .

8- Hirsch, A.(1991a): Which is Better Vacuum or Gas Packaging ? Ch.3In:Flexible Food Packaging. Questions and Answers, P.9. VAN Nostrand Reinhold, New York .

9-Hirsch, A. (1991b).Why is An Oxygen Barrier Required? Ch.4.In: Flexible Food Packaging. Questions and Answer, P.14 VAN Nostrand Reinhold. New York .

JHE, 2021, 31(2): pp 98 - 116 . يتم طباعتها في جامعة المنوفية، جميع حقوق الطبع محفوظة للمجلة. 
10- Hood, D.E. and Riodan, EB.(1973): Discoloration in Prepackaged beef: Measurement by reflectance spectrophotometery and Shopper discrimination. Food Technol., 8(3):333343.

11- Hood, D.E. (1980): Factors affecting the rate of metmyoglobin accumulation in prepackaged beef. Meat Sci.,4:247-265 .

12- Hotchkiss J.H. (1988): Moisture Transfer and Shelf-life of Packaged Foods. Ch.19.in : Food and Packaging Interactions, P.243.American Chemical Society, Washington .

13- Hunt, M.C. (1980): Meat Color Measurement. Proc.33 ${ }^{\text {rd }}$. Recip. Meat Conf. Nat'1. Live Stock and Meat Board, Chicago, IL.

14- Jenkins, W.A. and Harrington JP (1991):The Chemistry and Manufacture of Polymers Used in Packaging.Ch.4.In: Packaging Food with plastics, p.35.

15- Jeremiah, L.E. Carpenter AL and Smith GC.(1972): Beef color as related to consumer acceptance and palatability, J. Food Sci., 37:476-479.

16- Lanier, T.C:, Carpenter, J.A. and Toledo, R.T.(1977): Effect of cold storage environment on color of exposed lean beef faces. J. Food Sci., 42:860-864.

17- Ledward, D.A. (1984): In Developments in Food Proteins, Vol.3,Ed B.J.F. Hudson. Elsevier Applied Science, London, P.33 .

18- Lynch, N.M.; Kastner, C.L.; Caul J.F. and Kropf, D.H. (1986): Flavor Profiles of vacuum packaged and polyvinyl chloride packaged ground beef. A Comparison of cooked flavor changes occurring during product display. J. Food Sci.,51:258-262.

19- MacDougall, D.B.(1982): Changes in the color and opacity of meat. Food Chem.,75-79.

20- Mancini,R.A. and Hunt,M.C.(2005): Curent research in meat color. Meat Sci.,71:100 121

21- Meischen, H.W.; Huffman, D.L. and David, G.W (1987): Branded beef-product of tomorrow today. Proceeding of the reciprocal Meat Conference.J.Food Sci.; 40:37-46.

22- Mermelstein, N.H. (2002): More Packaging Papers and Exhibits. Food Technology, $56(6),: 70$.

23- Muricia, M.A.; Martinez-Tome, M.; Nicolas, M.C. and vera, A.M. (2003): Extending the shelf-life and proximate composition stability of ready to eat foods in vacuum or modified atmosphere packaging. Food Microbiology, 20(6):671-679 .

24- Pearson, D. (1970): The Chemical Analysis of Food. National Collegeof Food Technology, University of Reading, Weybridge, Surry J and Churcill, A, UK.

25- Pearson, R.B. (1982): PVC as a food packaging material. Food Chemistry, 8(2):85-69 .

JHE, 2021, 31(2): pp 98 - 116 . يتم طباعتها في جامعة المنوفية، جميع حقوق الطبع محفوظة للمجلة. 
26- Peter, F. and Axtell, B. (1993) : Appropriate Food Packaging. Publ. Transfer of Technology for Development, Amsterdam, International, Labour Office GENEVA.

27- Petersen, J.H.; Togeskov, P.; Hallas, J,; Olsen,M.B.; Rgensen, T.A.B. and Jakobsen M.(2004): Evaluation of retail fresh meat packaging covered whith stretch films of plasticized PVC and non-PVC alternatives. Packaging Technology and Science, 17(2):5366.

28- Rhee, K.S. and Ziprin, Y.A.(1978): Lipid oxidation in retail beef, pork and chicken muscles as affected by concentration of heme pigments and non heme iron and microsomal enzymic lipid peroxidation activity. J. Food Biochem., 11:1-5.

29- Risch, S.J. and Hotchkiss, J.H. (1991): Interactions of Food, Drug and Cosmetic Dyes with Nylon and Other Polyamides. Ch.4.In:Food and Packaging Interactions. II, P.37.American Chemical Society, Washington .

30- SASO (1986): Saudi Standard 457. Saudi Arabian Standards Organization, Riyadh, C.F. Meat Sci.,36:381.

31- Sekar, A .; Dushyanthan, K.; Radhakrishnan, K.T. and Babu, R.N.(2005): Effect of modified atmosphere packaging on structural and physical changes in buffalo meat. Meat Sci., 72.: 211-215.

32- Sheridan, J.J.; Doherty, A.M.; Allen, P.; McDowell, D.A.; Blair, I. and Harrington, D. (1997): The effect of vacuum and modified atmosphere packaging on the shelf-life of Leamb primals stored at different temperatures. Meat Sci.,45(1):107-117.

33- Smith, J.P.; Ramaswamy, H.S. and Simpson, B.K.(1990): Developments in food packaging technology. Part II: Storage aspects. Trends in Food Sci.,8,111-118 .

34- www.fao.org . CAC/RCP 1-1969

35- Young, L.L.; Reviere, R.D. and Cole, A.B,(1988): Food Technol, Spept,65,C.F.Meat Sci., 42(3):315-324(1996).

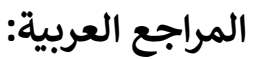

36- السباعي، ليلى ومهنا، نبيل (2000): تعبئة وتغليف الأغذية ومنتجات الألبان - منشاة المعارف - الإسكندرية.

37- الشريك، يوسف محمد ومروان، العارف غيث، عسكر، احمد عبد المنعم (1994): الاتجاهات الحديثة في

تصنيع وتداول الأغذية المجمدة - الطبعة الأولى - الدار العربية للنشر والتوزيع - القاهرة.

38- الشريك، يوسف محمد وعليان، محمد محمود (1996): تكنولوجيا اللحوم ومخلفاتها - الطبعة الأولى -

الدار العربية للنشر والتوزيع القاهرة.

JHE, 2021, 31(2): pp 98 - 116 ـ يتم طباعتها في جامعة المنوفية، جميع حقوق الطبع محفوظة للمجلة. 


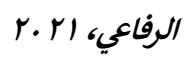

39- الشيباني، علي محمد حسين (1985): التقييم الغذائي لطرق تصنيع الأغذية - وزارة التعليم العالي والبحث العلمي - جامعة الموصل - العراق.

40- الهيئة العربية السعودية للمواصفات والمقاييس (2005): رقم. 116، لحوم البقر والجاموس والضأن والماعز المبردة والمجمدة، المملكة العربية السعودية. 41- خليفة، نداء ومنصور، محمد (1996): صحة اللحوم والأسماك - الطبعة الأولى - منشورات جامعة عمر المختار - البيضاء - ليبيا. 42- عبد الحميد، عبد الحميد محمد (1999): اضرار الغذاء والتغذية - الطبعة الاولى - دار النشر للجامعاتالقاهرة. 43- عبيدات، ذوقان (2003): البحث العلمي - إشراقات للنشر - الأردن.

JHE, 2021, 31(2): pp 98 - 116 ـ يتم طباعتها في جامعة المنوفية، جميع حقوق الطبع محفوظة للمجلة. 


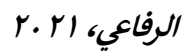

\title{
Packaging conditions and their effect on the color and shelf life of frozen lamb
}

\section{Nihal Mahmoud Al-Rifai}

Department of Nutrition and Food Science, Umm Al-Qura University, Kingdom of Saudi Arabia

\begin{abstract}
:
Subject Plan : In this research the following packaging materials (Polyethylene Low Density - Polyamide \Polyethylene - Polyvinyl used Chloride ), and the packaging carried out in air and under vacuum conditions for mutton meat which was in cubes without bone, cubes with bone and ground forms which are the famous forms used for mutton meats. Then packaging carried out for studied meat samples in above packaging materials under two types of studied packaging conditions. Study Purpose : Study of effect of same different packaging materials and conditions on the studied meat samples and study the physical, chemical, bacteriological and sensory (odor) properties at zero time and the changes in these properties during frozen storage at- $18^{\circ} \mathrm{c}$. During frozen storage the meat samples analyzed monthly for that these samples had rejected odor. This study the shelf - life of studied mutton meat samples during frozen storage at- cassied owt to $18^{\circ} \mathrm{c}$. More important results and recommendations : Using Polyamide I Polyethylene was better than Poly Vinyl Chloride, using Poly Vinyl Chloride was better than Polyethylene and the under-vacuum packaging was better than air packaging and the storage of meat without bone was better than with bone and more better than ground.
\end{abstract}

Key words: Polyamide, Polyethylene, Under-vacuum, Sheep meat, Odor

JHE, 2021, 31(2): pp 98 - 116 . يتم طباعتها في جامعة المنوفية، جميع حقوق الطبع محفوظة للمجلة. 